\title{
O PAPEL DAS COMPLEMENTARIDADES E HIERARQUIAS NO PROCESSO DE MUDANÇA INSTITUCIONAL: O CONTROLE EXTERNO E A ASSIMILAÇÃO DAS REFORMAS DOS ANOS 1990
}

\author{
THE ROLE OF COMPLEMENTARITIES AND HIERARCHIES IN THE \\ PROCESS OF INSTITUTIONAL CHANGE: INSTITUTIONAL \\ ACCOUNTABILITY AND THE ASSIMILATION OF STATE \\ REFORMING IN THE 1990s
}

EMILIANO RODRIGUES BRUNET ${ }^{1}$

RESUMO: As instituições exercem um papel fundamental na configuração e operação de um modelo de desenvolvimento econômico. No Brasil, desde os anos 1930 até os dias atuais, o dirigismo do Poder Executivo e a sua ampla margem de discricionariedade política constituem um traço marcante na estruturação e operação do ambiente institucional correlato ao desenvolvimento. As reformas dos anos 1990, enquanto tentativa de reconfigurar um modelo de desenvolvimento por meio da intervenção no ambiente institucional, reproduzem esta característica marcante. Todavia, a capacidade política de reformular um modelo de desenvolvimento sofre uma série de condicionantes. Dentre estas condicionantes, é de crucial interesse o complexo processo de interação e síntese entre as instituições introduzidas com a reforma dos anos 1990 e aquelas outras que já haviam se consolidado e fortalecido ao longo da trajetória político-institucional anterior. Acreditamos que, no âmbito dessa discussão, o exame do papel desempenhado pelas instituições de controle em um contexto de reformas pode ajudar a melhorar nossa compreensão dos mecanismos de mudança institucional. Que papel uma instituição relevante de controle externo, como o Tribunal de Contas da União (TCU), teria jogado no processo de endogeneização de novas instituições trazidas com a agenda reformista? No enfrentamento de tais questões, tomaremos como objeto de exame empírico algumas das respostas do TCU - seja no plano de sua reorganização administrativa, seja no exercício de sua atividade-fim - a determinadas reformas do ambiente institucional entre a segunda metade da década de 1990 e o início dos anos 2000. Avaliamos em que medida o caso

\footnotetext{
${ }^{1}$ Doutor em Ciência Política - IESP/UERJ. Promotor de Justiça do Ministério Público do Estado do Rio de Janeiro. Contato: brunet.emiliano@gmail.com.
} 
examinado apresenta as características de um processo de síntese, no contexto do qual se revela a influência que complementaridades e hierarquias podem exercer na assimilação de reformas no arcabouço institucional.

Palavras-Chave: Instituições; Mudança Institucional; Sínteses e complementaridades; Regulação e desenvolvimento.

ABSTRACT: Institutions play a key role in shaping and operating a model of economic development. In Brazil, from the 1930s to the present day, the executive branch's leadership and its wide margin of political discretion are a striking feature in the structuring and operation of the institutional environment related to development. The reforms of the 1990s, as an attempt to reconfigure a development model through intervention in the institutional environment, reproduce this striking feature. However, the political capacity to reformulate a development model undergoes a number of constraints. Among these constraints, the complex process of interaction and synthesis between the institutions introduced with the reform of the 1990s and those that had already consolidated and strengthened during the previous politicalinstitutional trajectory is of crucial interest. We believe that, in the context of this discussion, examining the role of control institutions in a reform context can help to improve our understanding of institutional change mechanisms. What role could a relevant external control institution, such as the Brazilian Court of Audit ("Tribunal de Contas da União" - TCU), have played in the process of absorbing new institutions brought with the reformist agenda? In facing such questions, we will take as an object of empirical examination some of the TCU's responses - whether in the context of its administrative reorganization or in the exercise of its final activity - to certain institutional environment reforms between the second half of the 1990s and the beginning of the 2000s. We evaluate if the case examined presents the characteristics of a synthesis process, in the context of which we may discuss how complementarities and hierarchies can influence the assimilation of reforms in the institutional framework.

KEY WORDS: Institutions - Institutional Change - Hierarchies and complementarities Regulation and development. 


\section{O CONTEXTO DAS REFORMAS DOS ANOS 1990}

Após a crise e declínio, ainda nos anos 1970, do modelo de desenvolvimento econômico baseado na substituição de importações, ao que se seguiram períodos de hiperinflação e aguda crise fiscal ao longo da década de 1980 até o início dos anos 1990, o Brasil passou a experimentar, especialmente sob a coalizão política que se forma com a eleição presidencial de Fernando Henrique Cardoso em 1994, uma ambiciosa tentativa de reforma institucional.

Tal agenda política encartava-se, naquela quadra histórica, em um processo amplo e globalmente difundido, caracterizado pela paradigmática difusão de modelos institucionais e práticas de governança tidos, de acordo com a retórica reformista, como fundamentais à superação da crise, sobretudo a crise fiscal, e à retomada do desenvolvimento econômico (Brunet, 2017). Antes mesmo das reformas dos anos 1990 no Brasil, tal paradigma já penetrara profundamente, ainda que com suas nuances e peculiaridades, a agenda política de outros países da América do Sul, como por exemplo a Argentina.

No caso brasileiro, tal processo se desenrolou a partir de uma empreitada capitaneada pelo Poder Executivo (Boschi e Lima, 2002). Para além da ênfase nas medidas de ajuste macroeconômico - operadas por meio das políticas fiscal, monetária e cambial -, a agenda reformista, no tocante ao assim denominado "aparelho do Estado" identificadas com o modelo de desenvolvimento anterior. Neste contexto, como observa Diniz (2013), os anos 1990 vieram representar uma inflexão na trajetória anterior do capitalismo brasileiro, estando esta mudança de rumo fortemente associada à tentativa de ruptura com o modelo nacional-desenvolvimentista e à prioridade a partir de então conferida à promoção de estabilidade econômica e de reformas estruturais.

Conforme destacado acima, tal esforço de engenharia institucional testemunhado ao longo dos anos 1990 no Brasil deve ser entendido em seu contexto mais amplo. De fato, os anos 1990 assistem à progressiva emergência, em diversos meios, de uma visão focada nas instituições como fator explicativo das diferenças internacionais no desenvolvimento econômico ${ }^{3}$. Como Chang (2011) observa criticamente, em um

\footnotetext{
${ }^{2}$ Confira-se, a respeito do sentido específico atribuído pela coalizão reformista a esta noção, o Plano Diretor da Reforma do Aparelho do Estado (BRASIL, 1995).

${ }^{3}$ Em diálogo com trabalhos seminais de Douglass North, a noção de que "boas instituições" têm um efeito causal sobre o desempenho econômico permeia diversos estudos relevantes como, por exemplo, os de Acemoglu, Johnson e Robinson (2001) ou ainda de Rodrik, Subramanian e Trebbi (2004). De acordo com a perspectiva defendida por Acemoglu, Johnson e Robinson, baseada no uso do processo colonial como variável instrumental, os índices de mortalidade experimentados pelos colonizadores europeus teriam influenciado as estratégias de colonização, ora fundando-se "novas Europas" (sic), ora estabelecendo-se estruturas essencialmente extrativistas. A estratégia colonial, assim determinada, seria decisiva na configuração das instituições originárias, estabelecendo estas últimas uma correlação forte com a estrutura institucional atual. Finalmente, segundo os atores, a
} 
ambiente de globalização econômica e com a intensiva participação de instituições como o Banco Mundial, o FMI, a OCDE e o Fórum Econômico Mundial, dentre outros, ganhou impulso a perspectiva de que a má qualidade institucional seria supostamente a causa primária do mau desempenho econômico em países em desenvolvimento, como o Brasil.

Sob o influxo de tais paradigmas, ao longo da segunda metade da década de 1990, com a vitória eleitoral da coalizão de poder identificada com o diagnóstico da necessidade de reformas institucionais, observaram-se profundas investidas governamentais na reconfiguração do ambiente institucional, notadamente daquele mais diretamente ligado à intervenção do Estado no domínio econômico. Este amplo conjunto de medidas foi introduzido no âmbito de um discurso oficial que enfatizava - ao menos retoricamente - uma ruptura com o passado, tendo ficado conhecido pelo rótulo de "Reforma do Estado"4.

Em setores economicamente estratégicos e historicamente associados ao modelo de desenvolvimento econômico anterior, como, por exemplo, os de energia, telecomunicações e transporte, um dos objetivos propalados da reforma consistia em combater o déficit das contas públicas e alavancar o investimento privado nessas frentes, a fim de gerar crescimento e expandir a oferta. Pressionado por uma aguda crise fiscal, o Estado brasileiro poria em marcha acelerada, especialmente na segunda metade dos anos 1990, um programa de reforma institucional centrado na transferência da execução de serviços públicos e de determinadas atividades econômicas estratégicas - até então concentradas nas mãos do Poder Público - a agentes privados. Para tanto, o governo lançou mão, mais frequentemente, de dois

estrutura institucional teria um efeito causal sobre as diferenças observáveis no desempenho econômico dos países que compõem a amostra. Já em Rodrik, Subramanian e Trebbi, o efeito explicativo das instituições como causa do desempenho econômico é discutido comparativamente com a geografia e o processo de integração como fatores explicativos concorrentes, alcançando os autores a conclusão de que a qualidade institucional teria um efeito preponderante no desempenho econômico. Releva observar que ambos os estudos, baseados em amostras amplas envolvendo países com trajetórias bastante distintas, adotam medidas de qualidade institucional (tais como rule of law, constraints on executive ou risk of expropriation) que embutem em si mesmas a concepção de que o melhor desempenho econômico não só pressupõe a potencial convergência para um determinado modelo institucional, como também a de que este mesmo modelo se caracteriza por um compromisso com a proteção da propriedade privada e a imposição de limites ao Poder Executivo. Para uma crítica às formas de mensuração de qualidade institucional utilizadas nos estudos anteriores e às inferências causais ali contidas, confira-se Glaeser et. al. (2004). Sob outro viés crítico, para uma problematização das conclusões dos estudos anteriormente citados a partir de um olhar aprofundado sobre o complexo tema da endogeneidade das instituições, confira-se Przeworski (2004).

4 A referência a tal processo sob o rótulo de "Reforma do Estado" - fortemente associada a uma perspectiva de reforma da Administração Pública a partir de um viés gerencialista - pode ser encontrada, v.g., em Bresser-Pereira (1998). 
instrumentos, a saber: as privatizações e as delegações ${ }^{5}$ Os mecanismos então escolhidos, dado o contexto existente, se articulavam com o discurso acerca da necessidade de soerguer uma nova matriz institucional, tida como compatível com o deslocamento de determinadas atividades complexas, estratégicas, onerosas e potencialmente lucrativas ao setor privado.

Uma breve análise do contexto será relevante para entender as balizas e referências desta tentativa de reconfiguração do ambiente institucional, o que constitui um percurso necessário para a posterior compreensão da forma como suas consequências foram assimiladas por instituições de controle altamente capacitadas e com forte enraizamento histórico, como o Tribunal de Contas da União (TCU), em um processo que definiremos como de mútuas implicações, marcado por afinidades e complementaridades institucionais. Isto porque se por um lado a mudança institucional endogenamente experimentada pelo TCU teve o processo de reformas capitaneado pelo Poder Executivo como seu móvel, por outro lado as respostas apresentadas pela Corte de Contas acabaram compondo, em contrapartida, o mosaico de condicionantes para a assimilação em concreto das reformas.

Passando ao exame do contexto, o conjunto de instituições através das quais o Estado brasileiro até então operava nos domínios econômicos aqui discutidos constituiu um dos focos das reformas, o que foi materializado, por exemplo, com a privatização do sistema Telebrás, concluída em 1998, com a reestruturação do holding formado pela Eletrobrás e suas subsidiárias em 1997 ou ainda com um amplo programa de concessão de rodovias que se iniciara já nos idos de 1994, com o Programa de Concessão de Rodovias Federais, sob a responsabilidade do extinto DNER $^{6}$ (BRASIL, 2003; 2005). Com este movimento, pretendia-se transferir a execução de uma série de atividades aos agentes privados que, ante a perspectiva de explorá-las economicamente, aportariam os almejados investimentos naqueles serviços. Transferia-se, por esta via, um segmento importante, substancial, da atuação do Estado naqueles domínios.

De fato, uma das características do arcabouço institucional preexistente, herdado de um modelo intervencionista do Estado no domínio econômico, consistia no fato de que as atividades de (i.) formulação das políticas e diretrizes para o setor, (ii.)

\footnotetext{
5 Os mecanismos em questão não são necessariamente excludentes. A privatização expressa a transferência ao particular da propriedade ou do controle de uma empresa estatal, de maneira que os sócios privados passam a explorar economicamente aquela atividade que até então era desempenhada por um ente da administração pública indireta. Já o termo delegação é amplo e indica genericamente a transferência a um agente privado da prerrogativa de prestar um serviço público. A titularidade do serviço e sua natureza continuam sendo públicas, de maneira que o particular para a ser o executor do serviço público, o que se dá normalmente quando este último possui uma expressão econômica. A concessão é o instrumento mais conhecido - e nos casos examinados também o mais frequente - através do qual se opera uma delegação nesses termos.

${ }^{6}$ A privatização da Rede Ferroviária Federal também se deu nesse período, tendo as sete malhas ferroviárias brasileiras sido concedidas à iniciativa privada entre os anos de 1996 e 1999 (BRASIL, 2005).
} 
planejamento e dosagem do investimento e do ritmo de expansão da oferta, (iii.) definição dos (tímidos) marcos regulatórios da prestação de cada um daqueles serviços e (iv.) a execução propriamente dita da atividade eram, todas elas, como anota Bemerguy (2008), até então endógenas ao Estado e suas empresas. Em outros termos, do ponto de vista institucional, dada a concentração, não haviam se desenvolvido e aprofundado tanto a especialização quanto a diferenciação funcional com relação a cada uma destas atividades.

Para além disso, a mudança do eixo do investimento e da execução material daquelas atividades do setor público para o privado - por si só um movimento complexo e delicado - geraria ainda uma série de outros efeitos que demandariam uma reconfiguração dos arranjos institucionais até então existentes.

Nessa linha, uma primeira consequência importante a ser notada diz respeito à mudança do próprio estatuto, isto é, da natureza e do regime jurídico da prestação daqueles serviços e exploração daquelas atividades econômicas. A literatura associa esta primeira consequência do programa de desestatização a um assim denominado processo de contratualização daquelas atividades (ARAGÃO, 2002; SOUTO, 2007).

A noção de contratualização indica, aqui neste contexto, que a entrada em cena do prestador particular do serviço de telecomunicação ou do explorador da atividade de geração de energia, por exemplo, acabaria por gerar, vis-à-vis do poder público e também do próprio cidadão - que a partir de então passa a ser visto precipuamente como usuário -, uma relação pautada pela ideia de reciprocidade de obrigações. Um dos desdobramentos mais notáveis desse processo de contratualização consistiu em que irrompesse no cenário, tanto para fazer face à complexificação destas novas relações como também para reduzir os custos de transação ${ }^{7}$, a necessidade de rearranjos institucionais que permitissem a produção e a garantia de um marco regulatório claro da atividade delegada.

Ademais, além de dar ensejo a um processo de contratualização das relações entre a tríade (a) Governo - (b) Prestador de Serviço/Explorador da atividade - (c) Usuário, as privatizações e delegações acabaram desagregando atividades como as de formulação da política para o setor, planejamento, regulação e execução, que até então estavam indistintamente concentradas nas mãos do governo e de suas empresas. Este segundo aspecto também é crucial para que se entendam as circunstâncias que envolveram o esforço de reengenharia institucional do qual as agências reguladoras fazem parte.

Ora, do ponto de vista do governo de então, e como corolário dos aspectos que acabamos de mencionar, o processo de delegação da execução de serviços públicos e

\footnotetext{
7 A perspectiva de redução de "custos de transação" é central no paradigma neoinstitucionalista que constitui um dos referenciais teóricos da agenda reformista dos anos 1990 no Brasil. Sobre o desenvolvimento teórico já clássico do paradigma que associa "boas instituições" à redução de "custos de transação" e, consequentemente, ao bom desempenho econômico, confira-se North (2018, p. 111-125).
} 
atividades econômicas estratégicas de grande envergadura a agentes privados não se

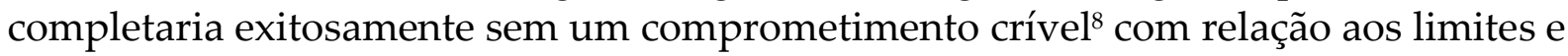
papéis do poder público na definição das políticas e diretrizes para o setor, bem como no tocante à regulação das atividades. Assim, se um novo modelo de investimento estava sendo posto em marcha, revelava-se incontornável, de acordo com aquele programa político, a necessidade de dotar o país de instituições supostamente capazes de encarnar compromissos que encorajassem o investimento por parte dos agentes econômicos interessados em assumir a execução daquelas atividades.

Assim, no âmbito do modelo de desenvolvimento então concebido, uma condição para a atração dos investimentos esperados dos agentes econômicos aos quais se transferiria a execução de serviços extremamente vultosos e complexos, como, por exemplo, os de telecomunicações ou de geração e distribuição de energia, era a diminuição dos custos de transação, o que envolvia em larga medida, segundo a concepção então dominante no âmbito do governo federal, a adoção de "boas instituições". Na prática, tais escolhas se traduziam na autolimitação da discricionariedade política, por meio da formalização de compromissos e redução de incertezas e riscos relativamente, por exemplo, à definição do marco regulatório que, a partir de então, regeria os serviços que o particular passaria a explorar economicamente.

Com relação a este aspecto, um traço essencial da estratégia adotada consistiu, portanto, na tentativa de alocar a regulação daquelas atividades econômicas em uma instituição - a Agência Reguladora - dotada de burocracia altamente especializada e teoricamente insulada do jogo político. Por esta via, tentava-se construir, a partir da reconfiguração do ambiente institucional, um comprometimento crível relativamente ao isolamento de aspectos essenciais da atividade econômica delegada (MELO, 2001) - notadamente em relação a temas como a não expropriação do investidor privado, a política tarifária e a política pública de investimento e expansão da oferta.

Dentro da retórica reformista, a construção deste comprometimento - ou pelo menos a tentativa - se daria em grande medida, como dito acima, com a introdução da figura das agências reguladoras, cujas leis criadoras lhes asseguravam prerrogativas tais como o mandato de seus diretores ou a pretensa blindagem do ato regulatório contra injunções políticas, notadamente naquilo que diz respeito aos aspectos técnicos da atividade. No âmbito deste projeto político de reforma institucional, temas como o equilíbrio econômico-financeiro dos contratos, a política tarifária, a administração dos bens vinculados à exploração da atividade econômica ou à prestação do serviço, dentre outros, estariam, segundo o discurso reformista, supostamente protegidos de injunções políticas que oferecessem risco aos investimentos privados que o governo pretendia atrair.

\footnotetext{
${ }^{8}$ Nesta passagem, nossa referência a credible commitment, nos termos de North e Weingast (1989), é, a exemplo da referência anterior à temática dos custos de transação, deliberada, dada a reconhecida inspiração das reformas dos anos 1990 no New Institutional Economics.
} 
Supostamente, substituía-se a discricionariedade política pela discricionariedade técnica, ainda que, como demonstram Boschi e Lima (2002), isto em nada ilida: i. o inegável protagonismo/dirigismo do Executivo no processo e ii. a interferência política nas agências. Como veremos, além dos aspectos levantados por Boschi e Lima, relativamente aos desvãos entre a retórica da reforma e a sua prática, a existência de hierarquias e complementaridades entre as instituições trazidas com a reforma e aquelas outras instituições que já existiam, como o TCU, acabaram modulando e afetando o desenho institucional originalmente imaginado pelo programa político reformador.

\section{PECUliaridAdes do ESFORÇO DE RECONFIGURAÇÃO DO AMBIENTE INSTITUCIONAL E SUAS CORRELAÇÕES COM O CONTROLE EXTERNO}

Como mencionado na seção anterior, um dos móveis do discurso reformista foi a crise fiscal. De fato, lastreando-se na alegada necessidade de reduzir o déficit fiscal por meio de privatizações e de cortes de gastos com o custeio da máquina pública, o programa de desestatização foi impulsionado, sobretudo, pela venda de ativos das empresas estatais e transferência da execução de atividades, até então tidas como custosas e deficitárias, para o setor privado.

Assim, a reconfiguração institucional se deu assimetricamente, tendo a transferência de atividades e serviços para o setor privado ocorrido em ritmo mais rápido, por exemplo, do que o desenvolvimento da capacidade de novos atores institucionais, como as Agências Reguladoras, ou a capacitação dos ministérios para a formulação de políticas e diretrizes nas respectivas áreas, dado que até a privatização eram as próprias empresas públicas que concentravam precipuamente estas atividades (BEMERGUY, 2008).

Com relação às Agências Reguladoras, por exemplo, seu corpo técnico foi inicialmente formado, em larga medida, com base em contratações temporárias cuja constitucionalidade foi duramente questionada (BANDEIRA DE MELLO, 2002), muitas vezes absorvendo através de contratos precários a mão de obra qualificada das empresas estatais privatizadas. A fragilidade do controle ministerial ${ }^{9}$ por parte do governo central - mesmo no campo que lhe é próprio, ou seja, o da formulação

\footnotetext{
${ }_{9}$ Uma característica das Agências Reguladoras é a sua vinculação, conforme a matéria, ao respectivo ministério. Assim, embora gozem de uma maior autonomia que as autarquias comuns, também submetidas a este tipo de vinculação, encontram-se em todas as leis de criação de agências reguladoras regras estipulando esta vinculação temática (ZYMLER, 2002). Nessa esteira, quando nos referimos à fragilidade do controle ministerial, queremos chamar atenção para o fato de que a dinâmica do processo de desestatização teve como uma característica marcante a não retenção, no âmbito do governo central, ao menos neste primeiro momento, de competências e capacidades relativamente a tarefas que, intuitivamente, não dizem respeito à regulação, como por exemplo a formulação das políticas do setor. Isso teve consequências importantes no processo de síntese institucional, inclusive nas relações entre o controle externo exercido pelo TCU e as Agências Reguladoras tema ao qual retornaremos adiante.
} 
das políticas e diretrizes - e a progressiva especialização das Agências Reguladoras dotadas de um corpo técnico que, ao menos inicialmente, ostentava um vínculo funcional de caráter precário, são apenas alguns dos fatores que fragilizaram o arcabouço institucional teoricamente adequado ao programa de desestatização.

Como consequência dessa dinâmica, no entender de Dallari (2003), eclodiram como aspectos problemáticos do novo arranjo institucional uma progressiva expansão da discricionariedade dos reguladores, sem contraponto no governo central, associada ao risco de captura das Agências pelos setores econômicos regulados. Ao lado das assimetrias organizacionais causadas pelo processo de desmobilização dos recursos humanos das extintas empresas estatais e da subsequente criação de Agências Reguladoras especializadas, a própria definição das atribuições que continuariam tocando ao governo central no âmbito de um novo modelo de Administração Pública gerencial restaram fluidas, o que teria redundado, de maneira bastante saliente em um primeiro momento, na tomada pelas Agências Reguladoras de decisões que tensionavam os limites do seu poder regulamentar e apresentavam uma discutível aderência às políticas do setor, como por exemplo se notava em decisões da ANP acerca da outorga de novos blocos de exploração de petróleo sem vinculação com a política energética nacional (BRASIL, 2003).

Nesta linha, a despeito de todas as apostas embutidas no processo de reconfiguração institucional que marcaram profundamente o período, a dinâmica das reformas e, sobretudo, seus resultados, acabaram por reafirmar que as heranças institucionais jogariam um papel fundamental no processo de síntese que viria a definir o alcance e as capacidades dos novos atores institucionais.

Parece-nos que, neste processo, o TCU acabou - não só em razão da dinâmica que o processo de reformas assumiu, mas também em razão das capacidades que acumulou historicamente, notadamente no que concerne à formação de uma burocracia altamente especializada e à progressiva assunção de papéis relevantes no controle da gestão pública ${ }^{10}$ - ocupando um papel saliente no controle das novas instâncias reguladoras, definindo limites e condicionantes para o exercício da função regulatória.

Noutras palavras, apesar do acentuado voluntarismo político e da inquestionável centralidade do Poder Executivo na condução da "Reforma do Estado", deve-se reconhecer que a trajetória política pretérita e o arcabouço institucional preexistente exerceram, por meio do estabelecimento de hierarquias e complementaridades, um papel tanto na assimilação quanto na definição do alcance das novas instituições e políticas associadas à aludida reforma (BOSCHI, 2013; BIZBERG, 2013). Bem a esse

${ }_{10}$ Um exame da trajetória institucional do TCU a partir das Constituições Brasileiras revela esta progressão a que acabamos de nos referir, tendo seus poderes e atribuições conhecido episódicas contrações em períodos ditatoriais. A Constituição de 1988 acabou por fixar as atribuições do TCU em bases inauditas, não só ampliando seus instrumentos de controle do Poder Público como também autorizando lhe a exercer o controle da Administração Pública com base em parâmetros bastante elásticos, como os da economicidade e da legitimidade. 
propósito, aliás, cabe desde logo clarificar que a referência que fazemos ao "arcabouço institucional" não se subsume a uma visão que simplifica e naturaliza as instituições como sujeitos em si mesmos, devendo abarcar também, dada a autonomia apenas relativa da ordem política, as relações de poder e os compromissos políticos que as instituições organizam e corporificam.

Relativamente ao receituário das reformas, já há relevante produção acadêmica dando conta de que, tanto no Brasil quanto alhures, este foi um processo que não gerou a imaginada convergência para um determinado modelo institucional ${ }^{11}$. Pelo contrário, por força das trajetórias pretéritas e dos compromissos institucionalizados, o que se verificou foram respostas variadas aos condicionantes da globalização econômica (BRESSER-PEREIRA, 2010; DINIZ, 2013).

Como fatores explicativos destas variadas respostas no período pós-neoliberal, têm-se, por exemplo, estudos que - focados no caso brasileiro (BOSCHI, 2013) ou mesmo na comparação de países da América Latina (BIZBERG, 2013) - utilizam como recurso analítico o mapeamento de hierarquias e complementaridades entre instituições que foram preservadas e as que foram introduzidas naquele período ${ }^{12}$.

É sob tais auspícios, portanto que passamos a buscar mapear tais complementaridades focando no controle externo do processo de desestatização nos setores de energia, telecomunicações e transporte, haja vista que a introdução do novo modelo regulatório nos anos 1990 gerou importantes fricções e ajustes com as atribuições fiscalizatórias do TCU (ZYMLER, 2002).

\section{MAPEAMENTO E ANÁLISE DAS RESPOSTAS INSTITUCIONAIS DO TCU}

$\mathrm{Na}$ presente seção buscaremos descrever e analisar qualitativamente algumas respostas institucionais do TCU, a fim de explorar seus impactos e complementaridades vis-à-vis da reforma institucional que se pretendeu introduzir ao longo dos anos 1990. O levantamento de dados recobre o período de 1990 a 2004. Tal horizonte temporal se justifica em razão do fato de que, ainda que de forma mais modesta, já no governo Collor, sobretudo na área de rodovias e no setor elétrico,

\footnotetext{
${ }^{11}$ Incorporando esta perspectiva, podem-se citar exemplificativamente estudos tanto no campo teórico da Varieties of Capitalism (HALL; SOSKICE, 2001) quanto no campo das análises regulacionistas (BOYER, 2012).

12 Como referencial teórico deste tipo de abordagem, cabe a remissão ao interessante trabalho de Amable e Palombarini (2009). Outros referenciais teóricos que permitem a problematização dos variados efeitos que uma mesma instituição idealmente concebida pode apresentar em contextos históricos e socioeconômicos específicos são aqueles que consideram seriamente o problema da endogeneidade das instituições (PRZEWORSKI, 2004) ou ainda aqueles que chamam a atenção para a diferença entre o ambiente institucional e os arranjos institucionais específicos que determinam no caso concreto a capacidade estatal de implementar com sucesso uma determinada intervenção (FIANI, 2014).
} 
algumas medidas de desestatização já haviam sido adotadas com base na Lei Federal no 8031/90, depois alterada pela Lei 9491/97 (Programa Nacional de Desestatização), peça importante do programa de reformas do governo FHC. O marco final do levantamento data de 2004 em razão da constatação de que a partir daquele ano o processo de assimilação das agências reguladoras no cenário institucional já se estabilizara - o que de alguma forma se reflete na rotinização da atividade fiscalizatória do TCU a acerca do tema a partir de então.

Ao nos referirmos a respostas institucionais englobaremos: (i) as adequações organizacionais implementadas pelo TCU em face do novo cenário, aí incluída a edição de novos regramentos internos e externos da fiscalização da desestatização e (ii) o exercício da atividade-fim, isto é as ações fiscalizatórias que redundaram na edição de decisões relevantes com relação à matéria.

A atenção às adequações organizacionais se justifica metodologicamente porque, no caso de uma instituição como o TCU, cujos procedimentos estão submetidos a um alto grau de formalismo, a readequação organizacional, além de bem documentada por meio de atos normativos, acaba se revelando um importante indício da forma como o Tribunal percebe e reage às novas demandas em termos de fiscalização.

De fato, em razão da amplitude de atribuições do TCU e de sua estrutura altamente especializada, a criação de unidades próprias e a realocação de pessoal para fazer face à fiscalização do processo de reformas constitui um indicador da disposição de investir no controle da desestatização e de capacitar-se para fazer face a este novo elemento. Além disso, a atenção aos regramentos editados no período mostra-se relevante na medida em que, do ponto de vista institucional, esta é a maneira como o TCU disciplina, junto ao seu corpo burocrático, o escopo e o modus operandi das práticas fiscalizatórias. Este é, também, um dos meios através dos quais o Tribunal se comunica com os entes fiscalizados estabelecendo responsabilidades.

Finalmente, as decisões proferidas no período representam aquilo que o Tribunal de fato apresentou como produto final da atividade fiscalizatória, o que, vale ressaltar, não esgota o potencial efeito constritivo de outros procedimentos de controle que podem não ter chegado necessariamente a uma decisão contendo determinações formais às agências reguladoras ou ao governo.

Com relação às decisões, constam da análise aquelas que atendam aos seguintes critérios: i. pertinência com o tema (desestatização e regulação) e ii. imponham, em seu conteúdo, algum tipo de restrição ou obrigação ao ente fiscalizado relativamente ao tema desestatização ${ }^{13}$. Destacaremos quatro linhas predominantes de ação do TCU: o uso das auditorias operacionais e instrumentos assemelhados como mecanismo de fiscalização global da organização e funcionamento das Agências Reguladoras, notadamente sob o viés estruturante da atividade regulatória; a

${ }_{13}$ Assim, por exemplo, ainda que se trate de uma decisão dirigida à ANEEL (ente criado com a desestatização do setor elétrico), a decisão só terá sido selecionada e analisada se, em seu conteúdo, contiver alguma determinação relativa à desestatização e/ou ao exercício da função regulatória (ex. política tarifária). 
tentativa de definição dos limites jurídicos e políticos daquilo que é a atividade regulatória; a cobrança, no âmbito da atividade fiscalizatória própria das Agências, de que estas últimas se capacitassem e fossem transparentes no exercício desta atividade e, finalmente, mostra-se bastante saliente a predominância do tema relativo ao equilíbrio econômico financeiro das concessões.

\subsection{Transformações organizacionais relevantes e produção normativa}

Do ponto de vista organizacional, releva notar que ocorreu perceptivelmente uma gradual e progressiva especialização do TCU à medida que avançava o programa de desestatização. Assim é que, se logo no início dos anos 1990, o programa de desestatização dava seus primeiros passos e ainda avançava timidamente com a edição da Lei Federal no 8.031/90 e a privatização da Usiminas, o processo de reconfiguração institucional representado pela venda de empresas estatais e pelo incremento das concessões de serviços públicos começa a se acelerar com a privatização da CSN e da EMBRAER, respectivamente, nos anos 1993 e 1994.

De forma análoga, o TCU, na fase inicial do processo, acompanhava a desestatização de forma descentralizada, não estando, ainda neste momento, dotado de estruturas específicas e de rotinas aprofundadas para lidar com a fiscalização da desestatização. O referencial normativo com base no qual o TCU exercia a fiscalização, nessa fase inicial, era a Instrução Normativa n. ${ }^{\circ}$ 07/1994, que dispunha sobre a "fiscalização dos processos de privatização de empresas incluídas no Programa Nacional de Desestatização criado pela Lei no ${ }^{\text {0 }}$ 8.031/1990". Naquele momento, a fiscalização era atribuída, ainda de forma fragmentada, nos termos da Instrução Normativa no 07/1994, “à Secretaria de Controle Externo do Tribunal de Contas da União a cuja clientela pertença a entidade".

Assim, embora o ponto focal de interação com o TCU no governo central fosse o "Gestor do Fundo Nacional de Desestatização", o controle externo do processo de desestatização no âmbito da estrutura organizacional da Corte de Contas ainda se dava de forma não sistêmica, ao menos em comparação com o incremento de capacidades organizacionais que se observaria logo em seguida.

À medida que o programa governamental avançou, o TCU foi aportando respostas relativamente rápidas que permitem inferir que o Tribunal, de alguma forma, não pretendia deixar que a agenda governamental ultrapassasse sua função fiscalizadora. Assim é que, tão logo aprovadas as duas principais leis federais em matéria de concessões de serviços públicos, as Leis nº 8.987/95 e no 9.074/95, o TCU editou um regulamento específico de fiscalização das concessões feitas pelo governo federal, através da Instrução normativa no 10/95.

Os anos correspondentes ao primeiro mandato de Fernando Henrique Cardoso (1995-1998) foram, indubitavelmente, o período de maior aceleração da agenda governamental de desestatização, tendo sido este o período no qual foram vendidas a ESCELSA, a Light, a Companhia Vale do Rio Doce e a Telebrás, tendo sido criadas, neste mesmo período, algumas das principais agências reguladoras, como a 
ANATEL (Lei Federal n.․ 9.472/97), ANEEL (Lei Federal no 9.427/96) e a ANP (Lei Federal $\mathrm{n}^{\mathrm{o}}$ 9.478/97). Pois foi neste mesmo período que o TCU aportou, em termos organizacionais e nas suas práticas, as respostas mais salientes ao programa de desestatização. Com efeito, data deste período a edição da Instrução Normativa $\mathrm{n}^{\mathrm{o}}$ $27 / 1998^{14}$, que trouxe relevantes consolidações e também inovações no âmbito do Tribunal, disciplinando, agora de forma específica e sistêmica, como seria feito o controle externo da desestatização, com isso criando deveres e responsabilidade também para as agências reguladoras, tendo esta sido a fonte de uma das primeiras e mais importantes fricções entre o TCU e as novas instituições então introduzidas com as reformas.

Enquanto resposta organizacional do TCU, a Instrução Normativa nº 27/1998 deve ser entendida no contexto em que se deu a dinâmica das reformas implementadas pelo governo federal. Um dos aspectos que mais chama atenção neste ato normativo prende-se justamente a uma das peculiaridades que mencionávamos na seção anterior, relativamente ao caminho que concretamente tomaram os esforços de reengenharia institucional.

Com efeito, na medida em que o processo de reforma não estabelecera um mandato claro para as agências reguladoras, definindo limites precisos entre as tarefas de formulação da política e de regulação, pode-se inferir que o TCU, através do referido ato normativo, pretendeu criar as condições para que as agências ficassem submetidas ao controle externo já na fase preparatória da outorga de uma atividade ao setor privado. De fato, como observa Zymler (2002, p. 23), uma das principais novidades da Instrução Normativa nº 27/1998 está em que ela "prevê o acompanhamento [pelo TCU] das concessões, permissões e autorizações de serviços públicos em dois momentos distintos, quais sejam: a) fase do acompanhamento da outorga e b) fase do acompanhamento da execução contratual."

Noutros termos, à vista dos caminhos que as reformas tomaram, dado que as agências reguladoras, na prática, não se limitavam a editar regulamentos e acompanhar a execução das atividades dos agentes econômicos delegados, o TCU houve por bem estender a fiscalização ao momento da própria outorga do serviço pelo governo ao agente econômico privado, assim procurando exercer um acompanhamento mais próximo da aderência das concessões às políticas do setor, aparentemente objetivando evitar aquilo que - no entender do TCU - poderia eventualmente configurar-se como um desvio de poder por parte das agências.

${ }_{14}$ Cabe anotar que, posteriormente à Instrução Normativa $n^{0}$ 27/1998, foram ainda editadas as Instruções Normativas 46/2007 (controle externo pelo TCU das concessões de rodovias federais) e no 52/2007 (controle externo da licitação e contratação de Parcerias Público-Privadas - PPP's). Atualizando e disciplinando mais detalhadamente os procedimentos de controle externo em relação às matérias acima mencionadas, foi recentemente editada a Instrução Normativa no 81/2018, abarcando a fiscalização de todos os processos de desestatização realizados pela Administração Pública Federal e revogando as Instruções Normativas nº 27/1998, no 46/2004 e no 52/2007. 
Outro aspecto relevante introduzido com a Instrução Normativa nº 27/1998 consistiu na preocupação em centralizar e especializar no TCU uma burocracia capaz de exercer de forma transversal e sistêmica o controle do programa de desestatização.

\subsection{Atividade finalística do TCU e condicionantes às reformas}

O exame do conjunto de respostas institucionais acima colacionadas já revela que a capacitação da Corte de Contas para a fiscalização e auditagem do processo de desestatização e a efetiva fiscalização da atuação dos novos atores institucionais visà-vis do governo central (e também dos agentes econômicos) constituíram a tônica dos movimentos empreendidos pelo TCU ao longo dos anos 1990 e início dos anos 2000.

Com efeito, o exame da atuação finalística confirma esta percepção. O exame de decisões relevantes proferidas no período em relação a áreas intensamente atingidas pela agenda reformista (como, por exemplo, as áreas de energia, telecomunicações e transportes), revela que o TCU atuou consistentemente em relação a quatro grandes eixos temáticos, a saber: 1. auditorias operacionais e decisões envolvendo o controle de aspectos organizacionais e de eficiência das Agências Reguladoras e/ou de outros atores institucionais afetos aos setores regulados; 2. definição dos limites jurídicos e políticos da atividade de regulação; 3. controle do efetivo exercício da função fiscalizatória pelas Agências Reguladoras e 4. controle do equilíbrio econômicofinanceiro das atividades reguladas.

Aprofundando cada um destes troncos temáticos ora propostos, destacamos logo abaixo, quanto ao eixo "auditorias e controle de aspectos organizacionais e de eficiência das Agências", decisões do TCU que envolvem um exame mais amplo e aprofundado da organização interna e dos procedimentos e rotinas que poderiam impactar a atuação do ente auditado. Assim, no período examinado foram objeto deste tipo de fiscalização, nos termos acima descritos:

- 1.a) no setor de energia (Petróleo, Gás e Energia Elétrica) - a Agência Nacional de Petróleo (ANP) foi alvo de Auditoria Operacional que resultou nas determinações contidas na Decisão no 981/2000 (Plenário), a qual abarcava, v.g., recomendações acerca das rotinas administrativas adotadas pela Agência e problemas envolvendo carência de pessoal para o escorreito desempenho das funções, dentre outras questões estruturantes. A realização de nova Auditoria Operacional na ANP, pouco tempo depois, resultou na Decisão no 243/2001 (2ª Câmara), contendo recomendações relativas à adoção de sistemas de tecnologia da informação ou ainda abordando a necessidade de adoção de metas e indicadores pela Agência, visando à mensuração da eficiência na fiscalização. A questão estruturante relativa à adoção de metas e indicadores por parte da ANP voltou a ser objeto, por exemplo, da Decisão no 553/2002 (2 ${ }^{\text {a }}$ Câmara). 
Ainda no setor de energia, a Agência Nacional de Energia Elétrica (ANEEL) foi objeto de abrangentes recomendações de caráter estruturante contidas na Decisão $\mathrm{n}^{\mathbf{o}}$ 833/2000 (Plenário), tendo a atuação do TCU, no caso sob comento, envolvido, por exemplo, o levantamento das condições organizacionais e dos sistemas utilizados pela Agência. A ANEEL voltaria a ser objeto de nova interpelação sob o viés estruturante de seu funcionamento por ocasião da Decisão n⿳ 276/2001 (2ª Câmara), no âmbito da qual se questionou, por exemplo, a utilização, pela agência, de "indicadores incompatíveis com o crescimento do setor elétrico".

- 1.b) no setor de transportes - a Agência Nacional de Transportes Terrestres (ANTT) também recebeu recomendações através do Acórdão nº 865/2003 (Plenário), que acompanhava o cumprimento do que fora determinado na Decisão no 427/2002, relativamente à regulação do transporte rodoviário interestadual e internacional, e ainda por ocasião da Decisão no 988/2004 (Plenário), originária de auditoria inicialmente realizada no DNER, mas contendo determinações à ANTT no tocante à execução de contratos de concessão de rodovias.

Em todas as decisões relatadas, algum tipo de recomendação foi feito pelo TCU. De qualquer modo, o que se afigura relevante desde logo é notar que, através daquela atividade finalística específica, o TCU se atribuía a função de aferir a eficiência operacional de algum ator pertinente aos setores regulados. Do ponto de vista analítico, o recurso às Auditorias como instrumento de fiscalização, sobretudo na modalidade de auditoria operacional, pode ter representado uma inflexão no padrão fiscalizatório do TCU (BEMERGUY, 2008), sendo cabível interpretar tal movimento como uma tentativa de oferecer um contraponto à dinâmica que assumiu o processo de reformas.

Já no segundo eixo acima mencionado, a saber, o da tentativa de definição dos limites jurídicos e políticos da regulação percebe-se que o TCU procurou prover respostas ante ao fato de que, da maneira como transcorreu a reforma, as Agências Reguladoras passaram a ter o poder de não só fiscalizar os serviços públicos concedidos como também o de efetuar diretamente novas outorgas. Um problema complexo relacionado a este dado da realidade consiste no fato de que a concessão de novas outorgas é um ato intrinsecamente relacionado à própria formulação da política, o que em princípio exorbitaria a função regulatória.

Observa-se que, nesses casos, o TCU proferiu decisões que ora questionavam as novas outorgas sob o prisma da sua não aderência (isto é, sua impertinência e/ou ausência de vinculação) à política do setor ou ainda decisões que, por outro prisma, questionavam o próprio objeto ou as condições da outorga que estava sendo lançada pela Agência Reguladora. Ainda neste eixo da tentativa de definição dos limites jurídicos e políticos da regulação podem-se encontrar decisões que não envolviam especificamente um controle das novas outorgas, mas da própria política do setor.

Assim, no período examinado foram, podem-se citar as seguintes decisões em torno do tema da definição dos limites jurídicos e políticos da regulação: 
- 2.a) no setor de energia - foram impostas à ANP decisões questionando o objeto ou as condições de novas outorgas em vias de serem concedidas, como se vê nas Decisões no 493/99 (Plenário), no 417/01 (Plenário) e 1574/02 (Plenário). Foi a ANP, ainda, alvo de decisões questionando a aderência de novas outorgas à política do setor energético, como se pode ler nas Decisões no 351/99 (Plenário) e 232/02 (Plenário).

- 2.b) no setor de telecomunicações - foram impostas à ANATEL decisões questionando o objeto ou as condições de novas outorgas em vias de serem concedidas, como se vê, v.g, nas Decisões nº 319/00 (Plenário), nº 182/01 (Plenário) e no 230/01 (Plenário).

Ainda com relação a este eixo analítico, merece particular menção a Decisão no 833/2000, no âmbito da qual o TCU determinou a adoção de providências, por parte do Ministério de Minas e Energia, com vistas à efetiva instalação do Comitê Nacional de Política Energética (CNPE), sendo certo que tal decisão, segundo se infere de seus fundamentos e de seu conteúdo, estava de alguma forma ligada à configuração de ponto altamente controverso no cerne daquele arranjo institucional, qual seja, o que diz respeito à possibilidade de as agências estarem, em tese, exorbitando de seu poder regulamentar, imiscuindo-se na formulação de políticas para o setor energético. Relativamente à ANP, por exemplo, o TCU fez observar que a concessão de novos blocos, isto é, a definição de novas áreas de exploração, era feita basicamente em função de critérios geológicos, com pouca articulação com a política energética e com os órgãos da área ambiental.

Um terceiro eixo importante de atuação do TCU consistiu no conjunto de decisões que impõem especificamente aos entes envolvidos no processo de regulação econômica uma atuação mais efetiva no processo de fiscalização dos agentes econômicos privados. Assim, no tocante à temática do controle do exercício da função fiscalizatória pelas Agências, podem ser citadas decisões do TCU revestidas não apenas de impacto econômico, como também social, como, v.g., o Acórdão n⿳o 787/2003 (Plenário), que impôs à ANP a adoção de mecanismos de controle social da regulação, sinalizando a necessidade de realização de audiências públicas de caráter regional, e apontou a necessidade de aderência entre os critérios de seleção dos blocos licitados e, quando adotada, a Avaliação Ambiental Estratégica.

Chegando ao quarto eixo temático de decisões consideradas relevantes, tem-se aquelas que dizem respeito à atuação do TCU relativamente ao equilíbrio econômicofinanceiro das concessões e delegações. De fato, com a mudança do regime de prestação de determinados serviços - referimo-nos aqui ao processo de contratualização antes descrito -, diversas atividades que até então eram exclusivamente públicas passaram a ter um caráter bifronte, exigindo a delicada conjugação do interesse social na prestação de um serviço adequado ${ }^{15}$ e do interesse

\footnotetext{
${ }^{15}$ Segundo o artigo 6o da Lei Federal no 8987/95, um dos principais atos normativos produzidos no período das reformas, um serviço considerado "adequado" deve atender a diversos critérios, como os da segurança, eficiência e da modicidade das tarifas.
} 
daquele que explora economicamente a atividade, consistente na remuneração de sua atividade basicamente através de tarifas e outras receitas alternativas.

Com relação a este delicado equilíbrio, esperava-se que as Agências Reguladoras, supostamente insuladas do jogo político, fossem capazes de estabelecer um marco regulatório e de fiscalizá-lo, com isso assegurando a adequação do serviço prestado, por um lado, e velando, por outro, para que as obrigações impostas ao prestador privado não pusessem em risco o equilíbrio-econômico financeiro do contrato de concessão, o que vale dizer, não comprometessem a margem de remuneração pactuada.

Seja como for, resta claro que toda e qualquer decisão relativamente ao equilíbrio econômico-financeiro de uma concessão acaba tendo um inegável caráter (re)distributivo, o que acabou por atrair sobre a decisões das Agências Reguladoras, notadamente nesta matéria, de um lado as expectativas difusas dos usuários relativamente à adequação dos serviços prestados, e de outro as pressões organizadas dos prestadores dos serviços.

Examinando-se as decisões proferidas pelo TCU no período, nota-se que a Corte de Contas buscou, com relativa frequência, desempenhar uma atividade corretiva da atuação das Agências Reguladoras no que concerne à questão do equilíbrioeconômico financeiro. O conjunto de decisões encontradas pode ser lido na chave de um contraponto a uma possível suscetibilidade das Agências Reguladoras à captura pelos prestadores do serviço.

Dentre as decisões relevantes do TCU acerca do tema, podem-se citar as que impugnam revisões tarifárias concedidas pelas Agências Reguladoras aos particulares que exploram economicamente determinada atividade, ou que impõem maior transparência e clareza quanto aos critérios que baseiam as revisões tarifárias. Sob este prisma, dados o seu poder de requisição de informações (inclusive do prestador do serviço), as suas atribuições e a sua posição sistêmica, o TCU teria podido contar, mais do que as próprias Agências Reguladoras, com um maior insulamento vis-à-vis dos interesses que podem influenciar as decisões em matéria de equilíbrio econômico-financeiro das concessões.

No período examinado, o TCU interpelou a ANEEL impugnando decisões da Agência em matéria de revisão das tarifas de energia elétrica ${ }^{16}$, como se vê nas Decisões n⿳o 1066/01 (Plenário) e n⿳0 1483/02. Quanto ao ponto, o Acórdão no 1756/03 (Plenário) veicula eloquente interpelação da ANNEL, pontuando "incertezas regulatórias que têm prejudicado o desenvolvimento do setor".

\footnotetext{
${ }^{16}$ Cabe anotar, quanto ao ponto, que em 2002 o TCU reforçou e sistematizou sua atuação fiscalizatória quanto ao tema ao baixar a Instrução Normativa no 43/2002 que dispunha sobre o "acompanhamento dos processos de revisão tarifária periódica dos contratos de concessão dos serviços de distribuição de energia elétrica". A IN 43/2002 foi recentemente revogada pela Instrução Normativa n 77/2017, que a atualiza.
} 


\section{CONCLUSÕES}

Nesta seção, a título de conclusão, procuraremos sintetizar os traços mais marcantes das respostas apresentadas pelo TCU diante do processo de reforma institucional dos anos 1990 - todos explicitados de forma mais detalhada na seção anterior -, procurando demonstrar em que medida tais movimentos podem ser analiticamente tratados sob a chave de uma síntese institucional, estruturada em torno de complementaridades, hierarquias e afinidades institucionais, que influenciaram os impactos inicialmente imaginados no âmbito da agenda reformista com a introdução da figura das Agências Reguladoras.

Um primeiro aspecto digno de nota é aquele concernente ao móvel das profundas transformações por que passou o TCU ao longo dos anos 1990. O exame dos dados explorados na seção anterior revela que, ainda que as reformas não sejam o único ou mesmo o principal motor do conjunto de transformações - veja-se que a Constituição de 1988 acabara de ampliar os poderes do TCU em um ambiente democrático -, o processo de reformas dos anos 1990 parece ter sido um importante fator indutor de uma série de reformulações relevantes, tanto na atividade-meio quanto na atividade finalística do TCU.

Além disso, outro aspecto que confirma o que se vem de dizer no parágrafo acima é o da sensível convergência entre a aceleração da agenda reformista na segunda metade dos anos 1990, já sob o governo de Fernando Henrique Cardoso, e a aceleração do processo de adequações organizacionais do TCU - como, por exemplo, com a edição da Instrução Normativa no 27/1998 -, o que sugere que a Corte de Contas buscou, em alguma medida, não se deixar ultrapassar pela dinâmica das reformas nem pela emergência de novos atores de peso, como as Agências Reguladoras, assim procurando exercer um papel relevante no processo de assimilação das reformas.

Substantivamente, tais respostas constituem um material relevante através do qual se podem compreender quais sentidos e valências o TCU atribuiu à dinâmica das reformas, mostrando-se salientes temas como o da definição dos limites jurídicos e políticos da regulação. Com efeito, dada a mudança do estatuto jurídico da prestação de diversos serviços relevantes - o que se deu com notáveis impactos políticos e econômicos -, o TCU parece ter procurado, como se vê de algumas das decisões citadas, se fazer intérprete daquilo em que consistiria, afinal, o cerne do exercício da função regulatória pelas Agências.

Tratava-se, em última análise, de iluminar as fronteiras entre a esfera regulatória e a esfera de formulação das políticas dos setores regulados. No desempenho deste mister, extrai-se do teor de decisões citadas no trabalho a tentativa do TCU de estabelecer balizas a partir das quais as Agências Reguladoras estariam exorbitando dos poderes regulatórios, ou seja, invadindo a esfera de formulação da política, tema que a Corte de Contas, desde logo, sinalizou devesse restar em mãos dos agentes sujeitos ao escrutínio político, notadamente o governo. 
Em outro flanco, despontam como tema recorrente na atividade de controle externo do TCU decisões que impugnam uma série de medidas adotadas pelas Agências Reguladoras relativamente à concessão de novas outorgas para a atuação de agentes econômicos do setor privado nas áreas, por exemplo, de exploração de petróleo ou distribuição de energia elétrica. Tratando-se de decisões que frequentemente questionam o objeto ou as condições das outorgas ofertadas no mercado pelas Agências Reguladoras, constata-se que o TCU utilizou como fundamento para tais impugnações a falta de clareza acerca da aderência destas outorgas às políticas do setor, tema que a Corte de Contas procurou sinalizar estar fora da esfera da regulação.

Um outro fundamento que, relativamente a este último conjunto de decisões, aparece com frequência é aquele relativo ao valor a ser oferecido pelo particular para a exploração de uma outorga. Este tema se avizinha daquele relativo ao do equilíbrio econômico financeiro dos contratos de concessão regulados pelas Agências. Quanto a este último ponto, são dignas de nota as decisões do TCU que questionaram revisões tarifárias (ou outras receitas) concedidas pelas Agências em favor dos agentes econômicos privados, sugerindo que, em alguma medida, a Corte de Contas procurou assumir uma posição de fiadora da não captura das Agências pelos setores regulados, no que nem sempre foi bem sucedida.

Em suma, ainda que seja dificílima a mensuração precisa do impacto econômico e político das decisões do TCU no funcionamento das agências reguladoras, o exame do material empírico acima colacionado sugere que, no âmbito de um processo de síntese institucional, algumas das respostas apresentadas pela Corte de Contas participaram nitidamente do processo de modulação dos efeitos da reforma, seja por meio do estabelecimento, reafirmação ou negociação de hierarquias institucionais, seja ainda pela definição de complementaridades e afinidades eletivas.

\section{REFERÊNCIAS}

ACEMOGLU, Daron; JOHNSON, Simon; ROBINSON, James A. The colonial origins of comparative development: An empirical investigation. American economic review, v. 91, n. 5, p. 1369-1401, 2001.

AMABLE, Bruno; PALOMBARINI, Stefano. A neorealist approach to institutional change and the diversity of capitalism. Socio-economic review, v. 7, n. 1, p. 123-143, 2008.

ARAGÃO, Alexandre Santos de. Agências Reguladoras e a Evolução Do Direito Administrativo Econômico . Rio de Janeiro: Editora Forense, 2002. 
BEMERGUY, Marcelo. O Papel do Controle Externo na Regulação de Serviços de Infra-estrutura no Brasil. Brasília: TCU, 2008.

BIZBERG, Ilán. Tipos de capitalismo en América Latina. Ciudad de Mexico, Mexico: El Colegio de Mexico, 2013.

BOSCHI, Renato. Politics and Trajectory in Brazilian capitalist development. In: Uwe Becker (Ed.). The BRICs and Emerging Economies in Comparative Perspective: Political Economy, Liberalisation and Institutional Change. London: Routledge, 2013.

BOSCHI, Renato e LIMA, Maria Regina Soares de. O Executivo e a Construção do Estado no Brasil: Do Desmonte da Era Vargas ao Novo Intervencionismo Regulatório. In: Werneck Vianna, L. A democracia e os três poderes no Brasil. Belo Horizonte: editora UFMG/IUPERJ, 2002.

BOYER, Robert. Diversité et évolution des capitalismes en Amérique Latine. De la régulation économique au politique. Révue de la Régulation [en ligne], 2012, 1ำ semestre, n. 11.

BRASIL. MARE - MINISTÉRIO DE ADMINISTRAÇÃO E REFORMA DO ESTADO. Plano Diretor da Reforma do Aparelho do Estado. 1995.

BRASIL. TRIBUNAL DE CONTAS DA UNIÃO. O controle externo das agências reguladoras. Questões relevantes sobre o setor de rodovias, de ferrovias e de transporte rodoviário de passageiros. 2005. Disponível em: <

https://portal.tcu.gov.br/biblioteca-digital/o-controle-externo-das-agenciasreguladoras-questoes-relevantes-sobre-o-setor-de-rodovias-de-ferrovias-e-detransporte-rodoviario-de-passageiros.htm>. Acesso em: 26 dez. 2018.

BRASIL. TRIBUNAL DE CONTAS DA UNIÃO. O controle externo das agências reguladoras. Questões relevantes sobre o setor elétrico e de petróleo e gás natural. 2003. Disponível em: < https://portal.tcu.gov.br/biblioteca-digital/o-controle-externodas-agencias-reguladoras-questoes-relevantes-sobre-os-setores-eletrico-e-depetroleo-e-gas-natural.htm>. Acesso em: 27 dez. 2018.

BRESSER-PEREIRA, L. C. Globalização e Competição. Por que alguns países emergentes têm sucesso e outros não? São Paulo: Elsevier-Campus, 2010. 
BRESSER-PEREIRA, L. C. Reforma do Estado para a Cidadania. A Reforma Gerencial Brasileira na Perspectiva Internacional. Brasília: ENAP, 1998.

BRUNET, Emiliano. Reforma do Estado no Governo Fernando Henrique Cardoso (1995-2002). Ideologia reformista, economicismo e direito em uma época de mudanças. Rio de Janeiro: Lumen Juris, 2017.

CHANG, Ha-Joon. Institutions and economic development: theory, policy and history. Journal of Institutional Economics, v. 7, n. 04, p. 473-498, 2011.

DALLARI, Adilson Abreu. Controle político das agências reguladoras. Interesse Público, Porto Alegre, n. 18, p. 13-20, 2013.

DINIZ, Eli. O Contexto Internacional e a Retomada do Debate sobre Desenvolvimento no Brasil Contemporâneo. In: Gaitán, Flávio e Del Rio, Andrés (orgs). Instituições Política e Desenvolvimento. América Latina Frente ao Século XXI. Curitiba: Editora CRV, 2013.

FIANI, Ronaldo. Arranjos Institucionais e Desenvolvimento: o Papel da Coordenação em Estruturas Híbridas. In: Gomide, Alexandre de Ávila e Pires, Roberto Rocha (orgs.). Capacidades Estatais e Democracia. Arranjos Institucionais de Políticas Públicas. Brasília: IPEA, 2014.

GLAESER, Edward L. et al. Do Institutions Cause Growth?. Journal of Economic Growth, v. 9, n. 3, p. 271-303, 2004.

MELO, Marcus André. A política da ação regulatória: responsabilização, credibilidade e delegação. Revista Brasileira de Ciências Sociais. São Paulo, vol. 16, n. 46, p. 56-68, 2001.

NORTH, Douglass. Instituições, mudança institucional e desempenho econômico. São Paulo: Três Estrelas, 2018.

NORTH, Douglass C.; WEINGAST, Barry R. Constitutions and Commitment: The Evolution of Institutions Governing Public Choice in Seventeenth-Century England. The Journal of Economic History, v. XLIX, n. 4, 1989.

PRZEWORSKI, Adam. The last instance: Are institutions the primary cause of economic development? European Journal of Sociology, v. 45, n. 2, p. 165-188, 2004. 
RODRIK, D.; SUBRAMANIAN, A. e TREBBI, F. Institutions rule: the primacy of institutions over geography and integration in economic development. Journal of Economic Growth, v. 9, n. 2, p. 131-165, 2004.

SOUTO, Marcos Juruena V. Direito Administrativo em debate. 2. ed. Rio de Janeiro: Lumen Juris, 2007.

ZYMLER, Benjamin. O papel do Tribunal de Contas da União no Controle das Agências Reguladoras. In: Fórum Administrativo. Belo Horizonte, v. 2, n. 11, p. 0307, 2002. 